\title{
Intensification of a mixing aeration tank operation by using hydraulic partitioning
}

\author{
Sergey Yu. Andreyev ${ }^{1} \cdot$ Nikolay E. Kurnosov $^{2} \cdot$ Michael I. Yahkind $^{3} \cdot$ Konstantin V. Lebedinskiy $^{2} \cdot$ Dmitriy P. Alekseev $^{2}$
}

Received: 4 September 2018 / Accepted: 16 October 2018 / Published online: 26 October 2018

(c) The Author(s) 2018

\begin{abstract}
The process of biological wastewater treatment in a mixing aeration tank for the purpose of its intensification is studied. Two variants of intensification are considered-hydraulic partitioning of aeration volume of the mixing aeration tank and use of a vortex aerator. It is proposed a calculation method of partitioning of aeration volume of the mixing aeration tank, and it is shown that partitioning can increase its performance by 1.8 times and reduce power consumption of the aeration system. The new design of the vortex aerator is described, and it is shown that its use will significantly increase the efficiency of the tank aeration system and intensify the process of biological treatment due to the increased turbulence of the activated sludge flow. In this case, the quantity of oxygen utilization rate is $\mathcal{K}_{\mathrm{u}}=0.14-0.18$, the relative concentration of organic contaminants is reduced to 0.20 at oxygen deficit $10 \%$ during the first aeration hour.
\end{abstract}

Keywords Mixing aeration tank $\cdot$ Wastewater $\cdot$ Aeration $\cdot$ Sludge mixture $\cdot$ Hydraulic aeration system $\cdot$ Hydraulic partitioning $\cdot$ Vortex aerator

\section{Introduction}

Currently, biological methods are considered to be the most widely used ones for the disposal of domestic and industrial wastewater. As a rule, the biological methods are cheaper and more efficient than the methods of physicochemical wastewater treatment. The ability of microorganisms to consume colloidal and dissolved substances as a source of energy and materials for maintaining their livelihoods is the basis of biological wastewater treatment processes. The biological methods include in vitro implementation of self-purification natural processes occurring in the natural environment.

In the world practice, continuous-flow aeration tanks are commonly used at the biological wastewater treatment plants in large cities.

Konstantin V. Lebedinskiy

lkv_mail@rambler.ru

1 Penza State University of Architecture and Construction, Penza, Russia

2 Penza State University, Penza, Russia

3 Penza State Technological University, Penza, Russia
The load distribution in the sludge along the aeration tank length is non-uniform, and it is a significant disadvantage of these structures. The organic contaminants concentration in the sludge mixture is maximal at the inlet of the aeration tank passage and intensely decreases as it approaches the outlet. The activated sludge biomass overburden for organic pollution at the inlet of the passage does not allow using this facility for treatment of highly concentrated wastewater.

The process of biological wastewater treatment in the mixing aeration tank for the purpose of its intensification is studied in this work. Two variants of intensification are considered-hydraulic partitioning of aeration volume of the mixing aeration tank and use of a vortex aerator.

\section{Experimental section}

\section{Theoretical background and calculation of mixing aeration tank}

Scientists don't recommend using a continuous-flow aeration tank without regeneration of the activated sludge for wastewater treatment, having a concentration of organic contaminants $\left(\mathrm{BOD}_{20}\right.$ ) of more than $150 \mathrm{mg} / \mathrm{L}$ (Henze et al. 2002; Voronov 2009). Using the technology of the activated 
sludge regeneration may allow to increase the concentration of organic contaminants at the continuous-flow aeration tank inlet up to $350 \mathrm{mg} / \mathrm{L}$ (Andreyev et al. 2017).

Continuous-flow aeration tanks can't be used in biological wastewater treatment of local facilities and small towns either.

Since such wastewater sewage facilities are of the unsteady drainage mode, significant fluctuations of the wastewater costs and concentrations of organic contaminants, therein, make it impossible to use continuous-flow aeration tanks.

In these cases, mixing aeration tank has become widespread, being bioreactors with a decentralized supply of wastewater and activated sludge.

The uniform distribution of the supplied wastewater to be treated and the returned activated sludge along the long side of the passage of this tank allowed providing their instantaneous mixing in the aeration volume that occurs under the influence of intensive cross-mixing. The same concentration of organic contaminants is set at all points along the passage length of the mixing aeration tank. The load on the activated sludge for organic pollution in this case is constant along the passage length. Its value depends on the volume of the aeration facility and may have an optimum value at high concentrations of organic contaminants in the wastewater applied to the mixing aeration tank.

The following simplified form of the material balance of wastewater flow, and the containing organic contaminants therein, corresponds to the formal scheme of the mixing aeration tank operation:

$Q_{\mathrm{h}} L_{\text {in }}=Q_{\mathrm{h}} L_{\text {out }}+V_{\mathrm{L}} W_{\mathrm{a}}=Q_{\mathrm{h}} \cdot L_{\text {out }}+V_{\mathrm{L}} Q_{\mathrm{h}} T_{\mathrm{a}}$,

$L_{\text {in }}=L_{\text {out }}+V_{\mathrm{L}} T_{\mathrm{a}}=L_{\text {out }}+\rho a(1-S) T_{\mathrm{a}}$,

where $Q_{\mathrm{h}}$ is an hourly wastewater flow, $\mathrm{m}^{3} / \mathrm{h} ; L_{\mathrm{in}}$ and $L_{\text {out }}$ are, respectively, concentrations of organic contaminants in wastewater inlet, and the sludge mixture at the outlet of the mixing aeration tank, $\mathrm{mg} / \mathrm{L} ; W_{\mathrm{a}}$ is the magnitude of the aeration volume of the mixing aeration tank, $\mathrm{m}^{3} ; V_{\mathrm{L}}$ is the volume rate of oxidation of organic contaminants with the activated sludge, $\mathrm{mg} / \mathrm{L} \mathrm{h} ; \rho$ is a specific rate of oxidation of organic contaminants with an ash-free substance of the activated sludge, $\mathrm{mg} / \mathrm{g} \mathrm{h} ; a$ is a sludge dose, $\mathrm{g} / \mathrm{L} ; S$ is the ash content of the sludge; and $T_{\mathrm{a}}=\frac{W_{\mathrm{a}}}{Q_{\mathrm{h}}}$ is the time of aeration of the sludge mixture in the mixing aeration tank (the aeration period), $h$.

From (2), we have

$L_{\text {out }}=L_{\text {in }}-\rho a(1-S) T_{\mathrm{a}}$,

$T_{\mathrm{a}}=\frac{L_{\text {in }}-L_{\text {out }}}{\rho a(1-S)}$
$\frac{L_{\text {in }}}{L_{\text {out }}}=1+\frac{V_{\mathrm{L}}}{L_{\text {out }}} \cdot T_{\mathrm{a}}=1+\mathcal{K}_{\mathrm{p}} T_{\mathrm{a}}$,

where $K_{\mathrm{p}}$ is the reaction rate coefficient, $\mathrm{h}^{-1}$ :

$\mathcal{K}_{\mathrm{p}}=\frac{\rho}{L_{\text {out }}} a(1-S)$.

The condition $\frac{\rho}{L_{\text {out }}} \approx$ const will be satisfied at a low concentration of organic contaminants $L_{\text {out }}(\mathrm{mg} / \mathrm{L} \mathrm{h})$ in the sludge mixture of the mixing aeration tank basin (the full biological wastewater treatment mode is $L_{\text {out }} \leq 20 \mathrm{mg} / \mathrm{L}$ ).

Since both $a$ and $S$ are constants, $\mathcal{K}_{\mathrm{p}}$, in turn, is a constant. In this case, the formula (2) can be written as:

$L_{\text {in }}=L_{\text {out }} \cdot\left(1+\mathcal{K}_{\mathrm{p}} T_{\mathrm{a}}\right)$,

wherefrom

$L_{\text {out }}=\frac{L_{\text {in }}}{1+\mathcal{K}_{\mathrm{p}} T_{\mathrm{a}}}$.

The main advantage of the mixing aeration tank used in the process of full biological treatment of small sewerage objects is its resistance to short-term fluctuations in the value of the load on the activated sludge for organic pollution.

The main disadvantage of the mixing aeration tank is a low specific oxidizing capacity $(\mathrm{OC})$ of the facility $(\mathrm{kg} /$ $\mathrm{m}^{3}$ day).

\section{Calculation of mixing aeration tank uses hydraulic partitioning}

The oxidative power of the mixing aeration tank operating in the biological treatment mode can be significantly improved by dividing its aeration volume by a number of serially connected cells.

The technological method of singling out a number of cells operating in the mixing aeration tank mode out of a total aeration volume, and connected in series with each other, is called hydraulic partitioning and used in cellular aeration tanks.

In hydraulic partitioning, the recirculating activated sludge and wastewater are fed to the first cell, where an intense mixing is done, and the same concentrations of organic mixture contaminants at all points of the cell aeration volume are set.

The sludge mixture passed the first cell of biological treatment and enters the second one. Since the concentration of organic contaminants in the sludge mixture in the first cell $L_{\text {out }_{1}}$ is higher than the concentration of organic contaminants in the sludge mixture in the second cell $L_{\text {out }_{2}}\left(L_{\text {out }_{1}}>L_{\text {out }_{2}}\right)$, where $K_{\mathrm{p}} \approx$ const, one can record (Andreyev et al. 2017)

Equation (2) can be written as: 
$K_{\mathrm{p}}=\frac{\rho_{1} a(1-S)}{L_{\text {out }_{1}}}=\frac{\rho_{2} a(1-S)}{L_{\text {out }_{2}}}=$ const.

From (7), we have $\rho_{1}>\rho_{2}$.

Thus, the technological method of hydraulic partitioning of the mixing aeration tank volume improves the average specific rate for organic contaminants oxidation with the ash-free substance of the activated sludge $\rho$.

For the cellular aeration tank composed of $n$-cells, the formula (6) can be written as:

$L_{\text {out }}=\frac{L_{\text {out }}}{\left(1+\mathcal{K}_{\mathrm{p} 1} T_{1}\right)\left(1+\mathcal{K}_{\mathrm{p} 2} T_{2}\right) \ldots\left(1+\mathcal{K}_{\mathrm{p} n} T_{n}\right)}$,

where $\mathcal{K}_{\mathrm{p} 1}, \mathcal{K}_{\mathrm{p} 2} \ldots$ are the reaction rate coefficients (rate of biochemical oxidation of organic contaminants in the cells of the aeration tank, $\left.\mathrm{h}^{-1}\right) ; T_{1}, T_{2}, T_{3}$ is the time of the biochemical oxidation of organic contaminants with the activated sludge in the aeration tank cells, $h$.

For the cellular aeration tank composed of two cells, the formula (8) takes the following form, provided $\mathcal{K}_{\mathrm{p} 1}=\mathcal{K}_{\mathrm{p} 2}=\mathcal{K}_{\mathrm{p}}$ :

$\frac{L_{\text {in }}}{L_{\text {out }}}=\frac{1}{\left(1+\mathcal{K}_{\mathrm{p}} T_{1}\right)\left(1+\mathcal{K}_{\mathrm{p}} T_{2}\right)}$.

Provided $T_{2}=0 ; T_{1}=T_{\mathrm{a}}$, the formula (9) can be written as:

$\frac{L_{\text {in }}}{L_{\text {out }}}=\left(1+\mathcal{K}_{\mathrm{p}} T_{1}\right)$.

Provided $T_{1}=T_{2}=0.5 T_{\mathrm{a}} ; \frac{T_{1}}{T_{2}}=1$, the formula (9) can be written as:

$\frac{L_{\text {in }}}{L_{\text {out }}}=\left(1+\mathcal{K}_{\mathrm{p}} T_{1}\right)\left(1+\mathcal{K}_{\mathrm{p}} T_{2}\right)=\left(1+0.5 \mathcal{K}_{\mathrm{p}} T_{\mathrm{a}}\right)^{2}$.

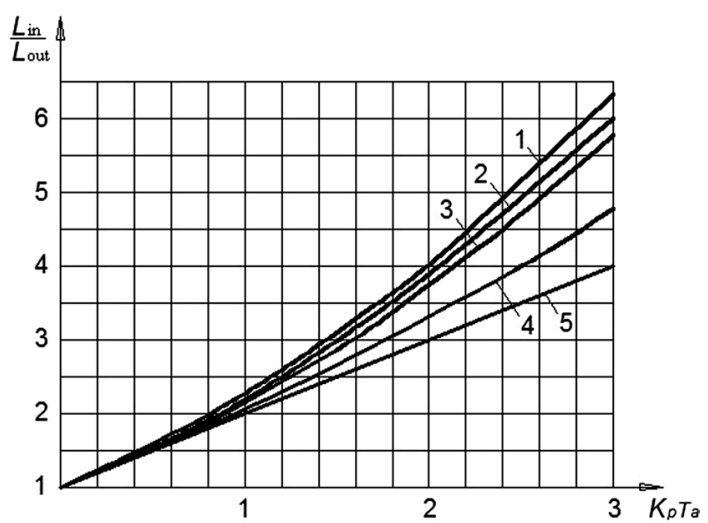

Fig. 1 Dependence graphs of the dimensionless quantity $\frac{L_{\text {in }}}{L_{\text {out }}}$ on the $\mathcal{K}_{\mathrm{p}} T_{\mathrm{a}}$ value
Figure 1 shows the dependence graphs of the dimensionless quantity $\frac{L_{\text {in }}}{L_{\text {out }}}$ on the $\mathcal{K}_{\mathrm{p}} T_{\mathrm{a}}$ value calculated using the formula (9) under various conditions of $\frac{T_{1}}{T_{2}}$ :

$1-\frac{T_{1}}{T_{2}}=1 ; 2-\frac{T_{1}}{T_{2}}=2 ; 3-\frac{T_{1}}{T_{2}}=3 ;$

$4-\frac{T_{1}}{T_{2}}=10 ; 5-T_{1}=T_{\mathrm{a}} ; T_{2}=0$.

The graphs presented in Fig. 1 show the cellular aeration tank to be more effective consisting of a number of cells of equal volume, if $K_{\mathrm{p}} \approx$ const, wherein $T_{1}=T_{2}=T_{n}$.

The resulting conclusion is valid, if $K_{\mathrm{p}}=K_{\mathrm{p} i} \approx$ const in all cells of the cellular aeration tank. Possibilities for intensification of the mixing aeration tank operation at a full-scale biological treatment mode due to the hydraulic partitioning can be illustrated by the example of the mixing aeration tank under the following conditions.

The aeration tank volume is $W_{\mathrm{a}}=B_{\mathrm{a}} \cdot L_{\mathrm{a}} \cdot H_{\mathrm{a}}=6 \cdot 6 \cdot 2$. $7=97 \mathrm{~m}^{3}$. The estimated daily capacity for the full-scale biological treatment of domestic wastewater is $Q_{\mathrm{d}}=200 \mathrm{~m}^{3}$.

The aeration period of domestic wastewater is

$T_{\mathrm{a}}=24 \frac{W_{\mathrm{a}}}{Q_{\mathrm{d}}}=24 \frac{97}{200}=11.6 \mathrm{~h}$.

The hourly wastewater flow fed into the aeration tank is (Andreyev et al. 2017)

$Q_{h}=\frac{W_{\mathrm{a}}}{T_{\mathrm{a}}}=\frac{97}{11.6}=8.4 \mathrm{~m}^{3} / \mathrm{h}$.

A concentration of organic contaminants $\left(\mathrm{BOD}_{\text {full }}\right)$ is $L_{\text {in }}=250 \mathrm{mg} / \mathrm{L}$ at the inlet of the mixing aeration tank, and it is $L_{\text {out }}=15 \mathrm{mg} / \mathrm{L}$ at the outlet of the mixing aeration tank. The estimated sludge dose, providing the aeration period value of $T_{\mathrm{a}}=11.6 \mathrm{~h}$ is $a=1.3 \mathrm{~g} / \mathrm{L}$.

To the first approximation, the aeration tank volume is divided into four equal parts, and the condition $K_{\mathrm{p}}=K_{\mathrm{p} i} \approx$ const is taken,

then

$L_{\text {out }}=\frac{L_{\text {in }}}{\left(1+C_{\mathrm{r}} T_{\mathrm{c}}\right)^{4}}$,

where $T_{\mathrm{c}}$ is the time of wastewater treatment in a single cell, h.

$$
\begin{aligned}
& T_{\mathrm{c}}=\frac{T_{\mathrm{a}}}{4}=\frac{11.6}{4}=2.9 \mathrm{~h} . \\
& C_{\mathrm{r}}=\left[\left(\frac{L_{\text {in }}}{L_{\text {out }}}\right)^{\frac{1}{4}}-1\right] \cdot \frac{1}{T_{\mathrm{c}}}=\left[\left(\frac{250}{15}\right)^{\frac{1}{4}}-1\right] \cdot \frac{1}{2.9}=0.352 \mathrm{~h}^{-1} .
\end{aligned}
$$


The calculated concentration of organic contaminants in the cells of the partitioned mixing aeration tank is defined as (Andreyev et al. 2017):

$$
\begin{aligned}
& L_{\mathrm{out}_{1}}=\frac{L_{\text {in }}}{1+C_{\mathrm{r}} T_{\mathrm{c}}}=\frac{250}{1+0.352 \cdot 2.9}=124 \mathrm{mg} / \mathrm{L} ; \\
& L_{\mathrm{out}_{2}}=\frac{L_{\mathrm{out}_{1}}}{1+C_{\mathrm{r}} T_{\mathrm{c}}}=\frac{124}{1+0.352 \cdot 2.9}=61 \mathrm{mg} / \mathrm{L} ; \\
& L_{\mathrm{out}_{3}}=\frac{L_{\mathrm{out}_{2}}}{1+C_{\mathrm{r}} T_{\mathrm{c}}}=\frac{61}{1+0.352 \cdot 2.9}=30 \mathrm{mg} / \mathrm{L} ; \\
& L_{\mathrm{out}_{4}}=\frac{L_{\mathrm{out}_{3}}}{1+C_{\mathrm{r}} T_{\mathrm{c}}}=\frac{30}{1+0.352 \cdot 2.9}=15 \mathrm{mg} / L
\end{aligned}
$$

As various concentrations of organic contaminants $\left(L_{\text {out }_{1}}>L_{\text {out }_{2}}>L_{\text {out }_{3}}>L_{\text {out }_{4}}\right)$ are observed in the cells of the sludge mixture of the aeration tank volume, the specific oxidation rates of organic contaminants with the ash-free substance of the activated sludge $\rho$ will also have different values.

On the basis of concepts of a bisubstrate enzymatic reaction with a two-phase enzyme replacement, the formula was obtained describing the dependence of the specific rate of oxidation $\rho(\mathrm{mg} / \mathrm{g} \mathrm{h})$ on the concentrations of organic contaminants $\mathrm{L}(\mathrm{mg} / \mathrm{L})$, and oxygen in the sludge mixture $C_{\mathrm{O}}(\mathrm{mg} / \mathrm{L})$, (Skirdov 1977) having the following form:

$\rho=\rho_{\max } \cdot \frac{L_{\mathrm{out}} \cdot C_{\mathrm{O}}}{L_{\mathrm{out}} \cdot C_{\mathrm{O}}+K_{1} \cdot C_{\mathrm{O}}+K_{\mathrm{O}} \cdot L_{\text {out }}} \cdot \frac{1}{1+\phi a}$,

where $\rho_{\max }$ is a maximum oxidation rate of organic contaminants with the ash-free substance of the activated sludge, $\mathrm{mg} /(\mathrm{g} \mathrm{h}) ; C_{\mathrm{O}}$ is the dissolved oxygen concentration in the sludge mixture, $\mathrm{mg} / \mathrm{L} ; K_{1}$ is a constant characterizing the properties of organic contaminants, $\mathrm{mg} / \mathrm{L} ; K_{\mathrm{O}}$ is a constant characterizing the impact of dissolved oxygen on the biological treatment, $\mathrm{mg} / \mathrm{L} ; L_{\text {out }}$ is a concentration of organic contaminants at the outlet of the mixing aeration tank, $\mathrm{mg} / \mathrm{L}$; $a$ is the activated sludge dose accepted on the basis of the efficiency of the secondary clarifiers, $\mathrm{g} / \mathrm{L}$; and $\phi$ is the inhibitory factor of the biological treatment with the activated sludge disintegration products, L/g (Andreyev et al. 2017).

Here are the values for domestic wastewater: $\rho_{\max }=85 \mathrm{mg} / \mathrm{g} \mathrm{h} ; K_{\mathrm{L}}=33 \mathrm{mg} / \mathrm{L} ; K_{\mathrm{O}}=0.625 \mathrm{mg} / \mathrm{L} ;$ and $\phi=0.07 \mathrm{~L} / \mathrm{h}$.

If we accept the value of the oxygen concentration in the sludge mixture as $C_{\mathrm{O}}=2 \mathrm{mg} / \mathrm{L}$, then, in accordance with the formula (12), we'll have:

$\rho_{1}=49.4 \mathrm{mg} / \mathrm{g} \mathrm{h} ; \rho_{2}=42.0 \mathrm{mg} / \mathrm{g} \mathrm{h}$;

$\rho_{3}=32.3 \mathrm{mg} / \mathrm{gh} ; \rho_{4}=22.2 \mathrm{mg} / \mathrm{gh}$.
The duration of the organic contaminant oxidation with the activated sludge in the cells of the aeration tank, in accordance with the formula (3), will be:

$T_{1}=2.8 \mathrm{~h} ; T_{2}=1.7 \mathrm{~h} ; T_{3}=1.1 \mathrm{~h} ; T_{4}=0.7 \mathrm{~h}$.

The real constant values of the biochemical oxidation reaction rate of organic contaminants with the activated sludge in the aeration tank cells calculated according to the formula (6) are (Andreyev et al. 2017): $\mathcal{K}_{\mathrm{p} 1}=0.363 \mathrm{~h}^{-1} ; \mathcal{K}_{\mathrm{p} 2}=0.608 \mathrm{~h}^{-1}$; $\mathcal{K}_{\mathrm{p} 3}=0.939 \mathrm{~h}^{-1} ;$ and $\mathcal{K}_{\mathrm{p} 4}=1.429 \mathrm{~h}^{-1}$.

The achieved parameters of the cellular aeration tank allow providing the condition to minimize the relations $\frac{L_{\text {out }}}{L_{\text {in }}}$ :

$\mathcal{K}_{1} T_{1}=\mathcal{K}_{2} T_{2}=\mathcal{K}_{3} T_{3}=\mathcal{K}_{4} T_{4}=$ const.

The total time of wastewater treatment in the cellular aeration tank is (Andreyev et al. 2017) $T_{\mathrm{ac}}=T_{1}+T_{2}+T_{3}+T_{4}=2.8+1.7+1.1+0.7=6.3 \mathrm{~h}$.

The hourly average of wastewater flow supplied to the cellular aeration tank is $Q_{\text {c. } h . \mathrm{c}}=\frac{W_{\mathrm{a}}}{T_{\mathrm{ac}}}=\frac{97}{6.3}=15.4 \mathrm{~m}^{3} / \mathrm{h}$.

$\bar{Q}=\frac{Q_{\text {c.h.c }}}{Q_{\text {c.h }}}=\frac{15.4}{8.4}=1.8$ times.

The efficiency of the aeration tank operation is significantly affected not only by the hydrodynamic mode of the aeration basin, but also by the perfection degree of the installed aeration system therein.

The aeration system means a complex of facilities and devices that supply microorganisms of the activated sludge with oxygen, and maintaining the activated sludge in suspension (the aeration volume mixing).

The hydraulic aeration system is most preferred for the mixing aeration tanks used in the biological wastewater treatment of local sewerage facilities and small settlements.

In operation of the hydraulic aeration system, there is the saturation of the aeration tank sludge mixture with oxygen due to air entrapment by falling jets or due to air entrainment by liquid jet moving through the narrowed portions of the ejection device. The hydraulic aeration systems use the flow energy of the sludge mixture delivered by a centrifugal pump. Unlike pneumatic aeration systems using blowers, the hydraulic aeration systems do not require the construction of a detached building to be heated, which significantly reduces the amount of capital expenditures for their construction.

\section{Design of a vortex aerator}

The laboratory of vortex processes and technologies of Penza State University (PSU) has developed a new design of the vortex aerator which significantly improves the efficiency of the hydraulic aeration system (Kurnosov et al. 2016). The PSU design of a vortex aerator model is shown in Fig. 2. 


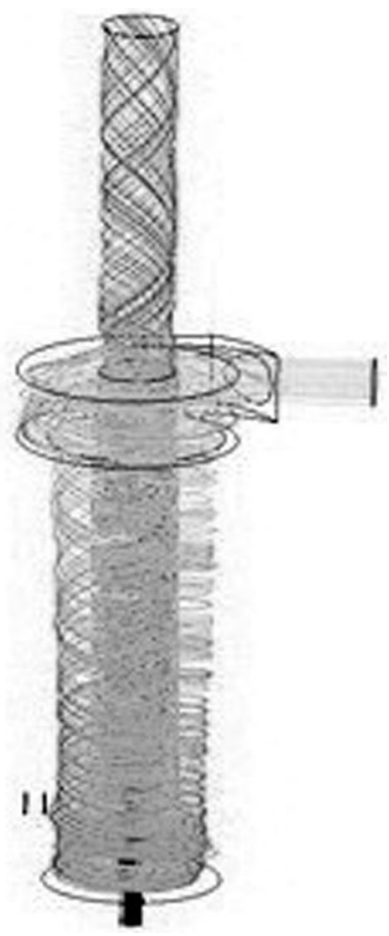

Fig. 2 A vortex aerator model of the PSU design

The vortex aerator works as follows. Liquid passing through the tangential inlet is twisted into a spiral flow under the influence of excess pressure and directed into the vortex chamber. Then it turns, and the reduced pressure zone is formed under the influence of centrifugal forces in the chamber. The air is sucked in, mixed with the liquid and removed. There is a highly efficient mass transfer due to the multi-directional high-speed swirling flow, liquid being saturated with oxygen.

\section{Results and discussion}

Tests have shown high efficiency of the vortex aerator. When the depth of the vortex aerator immersion is $H=2 \mathrm{~m}$, the coefficient of air ejection is $\mathcal{K}_{\mathrm{e}}=1.2-1.6 \mathrm{~m}^{3} / \mathrm{m}^{3}$, and the quantity of oxygen utilization rate is $\mathcal{K}_{\mathrm{u}}=0.14-0.18$.

The vortex aerator of the PSU design implements the principle of increased turbulence influence on the activated sludge. The increased turbulence observed in the aerator's vortex chamber allows to feed sufficient energy to the activated sludge flow for the deflocculating, which results in a rapid renewal of the interface between the sludge cotton and the environment, and provides an increase in the rate of nutrition and oxygen supply to the microorganisms, outflow of metabolic products, and ultimately leads to the increased rate of biochemical oxidation of organic substances.

The reduction in the activated sludge floc size causes an increase in the surface area of the phase interface "sludge

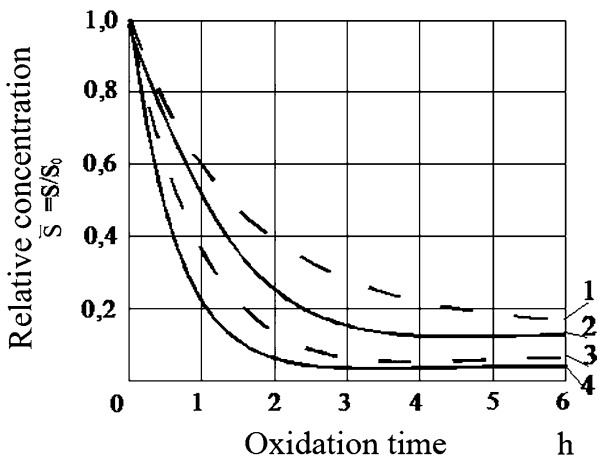

Fig. 3 The effect of oxidation time on the relative concentration of organic contaminants: $\breve{S}=S_{0} / S$ is the relative concentration of organic contaminants; $S_{0}$ is the initial concentration of organic contaminants, $\mathrm{mg} / \mathrm{L} ; S$ is the current concentration of organic contaminants, $\mathrm{mg} / \mathrm{L}$; dashed line is a $90 \%$ oxygen deficiency; solid line is a $10 \%$ oxygen deficiency; 1,2 are a $100 \mathrm{rpm}$ mixer; and 3, 4 are a $1200 \mathrm{rpm}$ mixer

cotton-wastewater' and increases the oxidation rate of biochemical contaminants. The influence of the mixing intensity on the wastewater biological treatment with the activated sludge was previously described (Evilevich and Braginsky 1979) (Fig. 3).

Increasing the number of the mixer revolutions from $100 \mathrm{rpm}$ to $1200 \mathrm{rpm}$ allowed to reduce the relative concentration of organic contaminants in wastewater $S^{-}$from 0.60 to 0.37 with an oxygen deficit of $90 \%$, and from 0.52 to 0.20 when oxygen deficit was $10 \%$ during the first aeration hour. As seen from the above data, the increased turbulence of the activated sludge flow not only significantly affects the rate of oxidation of organic contaminants, but also displaces oxygen limiting level.

The experimental data also showed that an increase in the mixing intensity of wastewater with the activated sludge can increase the effect of oxidation of organic substances from 88 to $96 \%$ or reduce the aeration period from 10.6 to $4.6 \mathrm{~h}$ without deteriorating the quality of wastewater treatment (Boyle and Rohlich 1966).

\section{Conclusions}

Given calculations and the experimental results on partitioning of the mixing aeration tank volume will improve its performance by 1.8 times and reduce power consumption of the aeration system.

Using the vortex aerator of the PSU design will significantly increase the efficiency of the tank aeration system and intensify the process of biological treatment due to the increased turbulence of the activated sludge flow. In this case, the quantity of oxygen utilization rate is $K_{\mathrm{u}}=0.14-0.18$,

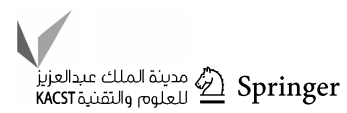


the relative concentration of organic contaminants is reduced to 0.20 at oxygen deficit $10 \%$ during the first aeration hour.

Open Access This article is distributed under the terms of the Creative Commons Attribution 4.0 International License (http://creativeco mmons.org/licenses/by/4.0/), which permits unrestricted use, distribution, and reproduction in any medium, provided you give appropriate credit to the original author(s) and the source, provide a link to the Creative Commons license, and indicate if changes were made.

\section{References}

Andreyev SY, Serpokrylov NS, Demidochkin VV (2017) Biological treatment of wastewater in aeration tanks: theoretical bases for process calculations. Environ Qual Manag 26(4):57-64. https:// onlinelibrary.wiley.com/doi/abs/10.1002/tqem.21504

Boyle WC, Rohlich GA (1966) Scale-up of the activated sludge process. Biotechnol Bioeng 8(3):405-431. https://onlinelibrary.wiley .com/doi/abs/10.1002/bit.260080308
Evilevich ML, Braginsky LN (1979) Optimization of biological wastewater treatment. Stroyizdat, Leningrad (in Russian)

Henze M, Harremoës P, la Cour Jansen J, Arvin E (2002) Wastewater treatment: biological and chemical processes. Springer, Berlin

Kurnosov NE, Lebedinskiy KV, Nikolotov AA, Alekseev DP, Inozemtsev DS, Agafonov SS (2016) (VKM Penza) Mass-transfer apparatus. Russian Patent 2576056, 27 Feb 2016

Skirdov IV (1977) Research and development of the intensification methods of work of facilities for biological treatment of wastewater. Doctor Dissertation, All-Union R\&D Institute of water supply, sewerage, hydraulic facilities and engineering hydrogeology, Moscow (in Russian)

Voronov YV (2009) Sewage and wastewater treatment. Association of Construction Higher Schools, Moscow (in Russian)

Publisher's Note Springer Nature remains neutral with regard to jurisdictional claims in published maps and institutional affiliations. 